Pemetaan Bawah Permukaan ...

\title{
PEMETAAN BAWAH PERMUKAAN PADA DAERAH TANGGULANGIN, SIDOARJO DENGAN MENGGUNAKAN METODA GROUND PENETRATING RADAR (GRP)
}

\author{
Elfarabi, Amien Widodo dan Firman Syaifudin \\ Teknik Geofisika, Fakultas Teknik Sipil dan Perencanaan, Institut Teknologi Sepuluh Nopember \\ elfarabi.amien@gmail.com
}

\begin{abstract}
Abstrak. Pengukuran dengan menggunakan Ground Penetrating Radar (GPR) dilakukan di kawasan lumpur Sidoarjo tepatnya di daerah Tanggulangin, Sidoarjo, agar dapat memetakan bawah permukaan di daerah ini. Ground Penetrating Radar adalah metoda geofisika yang dikembangkan sebagai salah satu alat bantu untuk penelitian geologi bawah permukaan dangkal dengan menggunakan prinsip dari gelombang elektromagnetik dan memiliki hasil yang rinci. Penelitian ini dilakukan di utara pusat semburan lumpur dengan mengambil data sebanyak 8 lintasan, setelah itu data di olah menggunakan software MatGPR R3-5. Berdasarkan hasil pengolahan data diketahui bawah permukaan pada daerah penelitian sudah tidak stabil hal ini dikarenakan efek dari semburan Lumpur Sidoarjo.
\end{abstract}

Kata Kunci- Ground Penetrating Radar (GPR), Lumpur Sidoarjo, Pemetaan bawah permukaan

\begin{abstract}
Measurements with Ground Penetrating Radar (GPR) has been applied for subsurface imaging of Sidoarjo's Mud Volcano eruption in Tanggulangin, Sidoarjo. Ground Penetrating Radar is geophysical method which develop as one of devices for low subsurface geological research that use electromagnetic wave principle and it has very detailed result. This research is located in the north side of the mudflow center used data from 8 line, then the data was processed using MatGPR R3-5 software. Based on the processing result is known that subsurface in the measurement areas are unstable caused by the Sidoarjo's Mud Volcano Eruption.

Key Word- Ground Penetrating Radar (GPR), Sidoarjo Mud Volcano Eruption, Subsurface Imaging
\end{abstract}

\section{PENDAHULUAN}

Lumpur panas yang keluar dari bawah permukaan dengan volume $50.000 \mathrm{~m} 3 /$ hari yang terjadi di beberapa lubang semburan, yang akhirnya menjadi satu lubang dengan volume lumpur panas yang dikeluarkan mencapai $126.000 \mathrm{~m}^{3} /$ hari pada bulan Mei-Agustus 2006. Melihat besarnya volume lumpur yang dikeluarkan diyakinkan bahwa akan terjadi amblesan di daerah tersebut, jika terjadinya amblesan yang dikarenakan oleh keluarnya lumpur ke permukaan, maka disekitar amblesan akan terjadi rekahan atau kerusakan bangunan. Oleh karena itu, perlu dilakukan penelitian lebih lanjut untuk mengkaji bawah permukaan untuk memberi informasi kondisi bawah permukaan.

Pada penelitian ini bertujuan untuk mengetahui gambaran bawah permukaan di kecamatan Tanggulangin, Sidoarjo dengan menggunakan metoda geofisika yaitu Ground Penetrating Radar (GPR). Metode GPR dipilih karena dapat digunakan sebagai alat bantu penelitian geologi bawah permukaan, pemetaan bawah permukaan dangkal, dan metoda ini memiliki resolusi yang tinggi (Budiono, dkk, 2010). Penelitian ini memetakan bawah permukaan karena agar dapat melihat potensi rekahan dangkal bawah permukaan yang disebabkan oleh amblesan.

\section{TINJAUAN PUSTAKA}

Metoda Ground Penetrating Radar (GPR)

Ground Penetrating Radar (GPR) pada bidang geofisika sering dikenal sebagai Ground Radar atau Georadar, metoda geofisika ini menggunakan sinyal gelombang elektromagnetik. Gelombang elektromagnetik akan dipancarkan ke dalam bumi dan direkam oleh antena pada saat gelombang telah mencapai kepermukaan. Gelombang elektromagnetik diteruskan, dipantulkan dan dihamburkan oleh struktur permukaan dan anomali jika terdapat di bawah permukaan. Gelombang elektromagnetik yang dipantulkan dan dihamburkan akan direkam oleh antena di permukaan. Metoda ini dapat menghasilkan gambaran bawah permukaan dengan resolusi yang tinggi, karena gelombang yang 
dipancarkan oleh GPR memiliki frekuensi sekitar 10 - $1000 \mathrm{Mhz}$.

Teknik penggunaan metoda Ground Penetrating Radar adalah sistem Electromagnetic Subsurface Profiling (ESP), dengan cara memanfaatkan pengembalian gelombang elektromagnetik yang dipancarkan melalui permukaan tanah dengan perantara antena. Pemancaran dan pengembalian gelombang elektromagnet berlangsung cepat sekali yaitu dalam satuan waktu nanosecond (Allen, 1979).

Persamaan Gelombang Elektromagnetik

Metoda Ground Penetrating Radar didasrkan atas permasamaan Maxwell yang merupakan rumus matematis untuk hukum-hukum alam yang mendasari semua fenomena elektromagnetik. Persamaan Maxwell dirumuskan sebagai berikut:

Error! Reference source not found.

Error! Reference source not found.

Error! Reference source not found.

\section{Error! Reference source not found.}

Dimana:

Error! Reference source not found. = Medan Listrik (N/C)

Error! Reference source not found. = Medan Magnet (Tesla)

Error! Reference source not found. = Permitivitas Listrik dalam ruang hampa (8.85 $10^{-12} \mathrm{C}^{2} / \mathrm{Nm}^{2}$ )

Error! Reference source not found. = Tahanan Jenis (ohm)

Error! Reference source not found. = Permeabilitas Magnetik ( $\mathrm{H} / \mathrm{m})$

Error! Reference source not found. = Rapat Arus Listrik $\left(\mathrm{A} / \mathrm{m}^{2}\right)$

Persamaan Maxwell untuk medium isotropis heterogen dirumuskan sebagai berikut:

Error! Reference source not found.

(5)

Error! Reference source not found.

(6)
Error! Reference source not found.

(7)

Error! Reference source not found.

(8)

Dimana:

Error! Reference source not found. = Konduktivitas (ohmmeter)

Error! Reference source not found. = Intensitas Medan Magnet $(\mathrm{A} / \mathrm{m})$

Setelah itu dapat dirumuskan kecepatan gelombang elektromagnetik sebagai berikut:

Error! Reference source not found.

(9)

Dimana:

Error! Reference source not found. = Kecepatan Gelombang Elektromagnetik

Error! Reference source not found. = Kecepatan Cahaya

Error! Reference source not found. = Konstanta Dielektrik Relatif

Error! Reference source not found. = Permeabilitas Magnetik Relatif $(\mathrm{H} / \mathrm{m})$

Error! Reference source not found. = LosS Factor Error! Reference source not found.

\section{Geologi Regional}

Daerah Tanggulangin dan Pusat semburan termasuk pada cekungan Jawa Timur Utara. Cekungan Jawa Timur Utara dibagi menjadi tiga bagian yaitu; bagian selatan (gunung api aktif); bagian cekungan laut trangresi; dan bagian utara (pegunungan). Di bagian tengah terjadi pembentukan terumbu karang (reff) dan pengendapan sediment klastik yang bersumber dari utara. Bersamaan dengan itu terjadi aktivitas tektonik dan letusan gunung api yang berlangsung secara terus-menerut, hal ini mengakibatkan tertutupnya lapisan sedimen. Aktivitas tektonik tersebut mengakibatkan struktur daerah tersebut menjadi kompleks yaitu antara struktur lipatan, patahan, dan diapir. Oleh karena itu didaerah tersebut menjadi target utama pencarian minyak bumi atau gas bumi (Widodo 2007). 


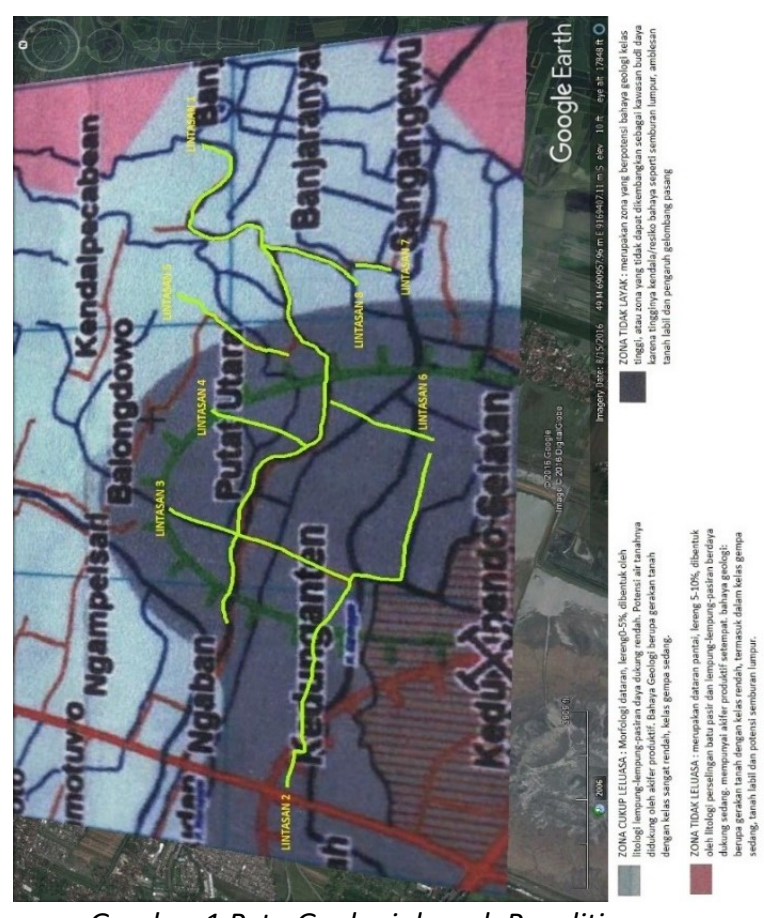

Gambar 1 Peta Geologi daerah Penelitian

Berdasarkan peta geologi tata lingkungan Kabupaten Sidoarjo, yang diterbitkan oleh Pusat Lingkungan Geologi (Badri dll, 2007), menjelaskan bahwa kecamatan Tanggulangin sebagian besar termasuk pada zona tidak layak karena, termasuk pada zona yang berpotensi bahaya geologi kelas tinggi, zona ini juga termasuk zona yang memiliki resiko semburan lumpur, amblesan tanah labil.

\section{Amblesan}

Amblesan (subsidence) adalah gerakan ke bawah di permukaan bumi dari suatu datum, sehingga elevasi muka tanahnya berkurang atau menjadi lebih rendah dari semula. Kebalikannya adalah pengang-katan (uplift) yang menghasilkan naiknya permukaan atau elevasi permukaan tanahnya bertambah.

\section{METODOLOGI PENELITIAN}

Lokasi penelitian Tugas Akhir ini dilakukan di daerah kecamatan Tanggulangin, Sidoarjo, Jawa Timur, dengan jumlah pengukuran di delapan lintasan seperti yang ditunjukan pada gambar 2 .

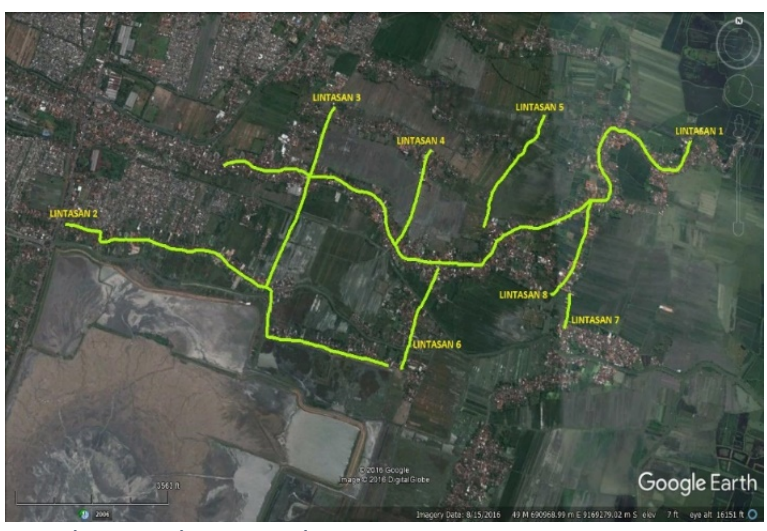

Gambar 2 Lokasi Penelitian

Setelah dilakuakan pengambilan data di lapangan, dilakukan pengolahan data berdasarkan diagram alir pada gambar 3 .

Mean spatial filter bertujuan untuk mengurangi noise yang berfrekuensi tinggi dan noise yang tidak beraturan. Dilakukannya mean spatial filter ini diharapkan agar memperkuat sinyal amplitudo dan melemahkan noise amplitudo. Pada pengolahan data mean spatial filter peneliti mencari parameter yang paling optimal dalam dimensi "time axis" dan "scan axis". Pada pengolahan mean spatial menggunakan time axis 1 dan scan axis 5 karena dianggap paling optimal. 


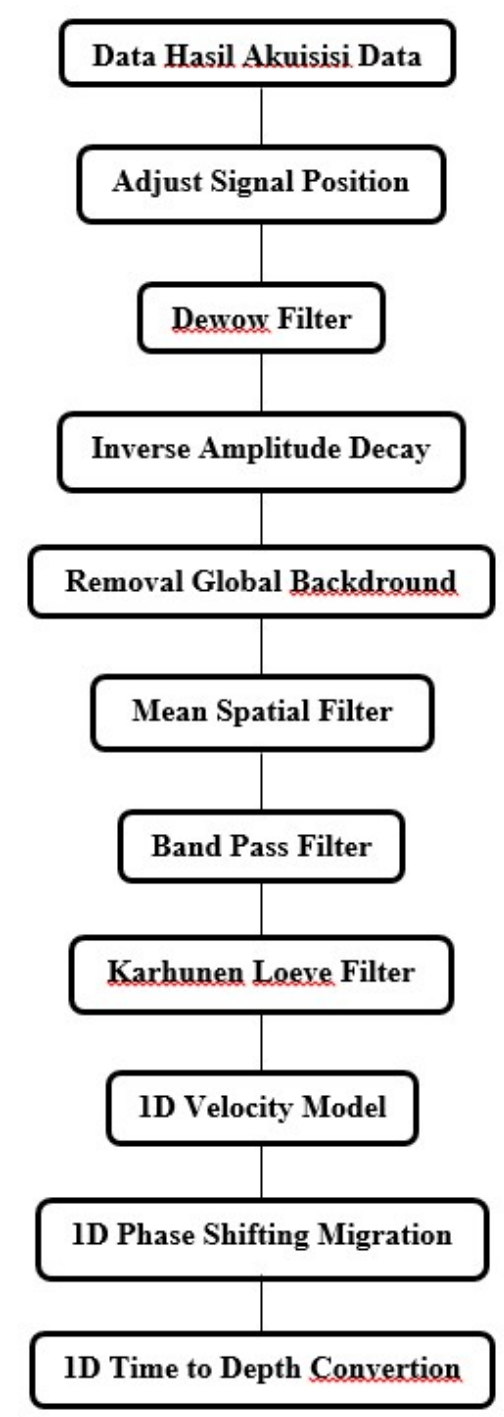

Gambar 3 Digram Alir Pengolahan Data

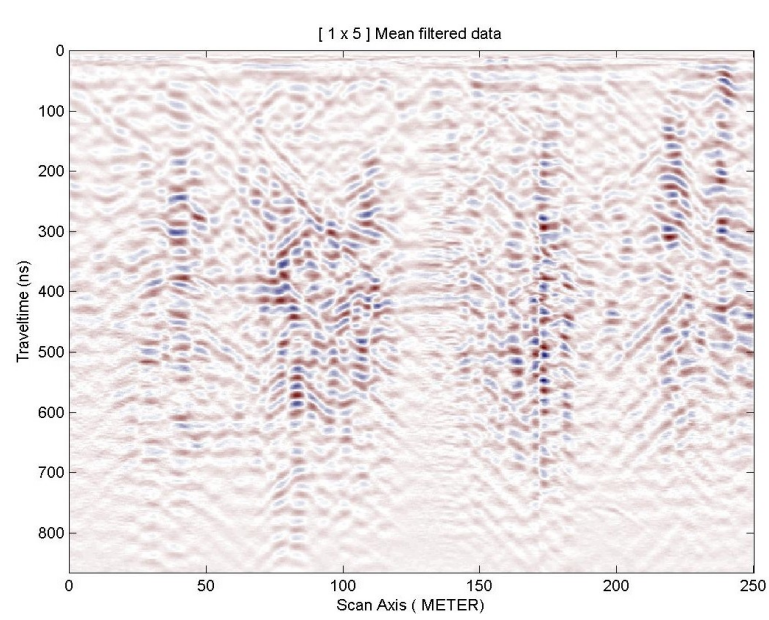

Gambar 4 Hasil setelah dilakukan proses mean spatial filter dengan time axis 1 dan scan axis 5
Karhunen Loeve Filter, filter ini digunakaan agar dapat menghilangkan atau mengurangi noise lateral dengan memanfaatkan transformasi Karhunen Loeve. Pada pengolahan data karhunen loeve filter peneliti mencari parameter number of largest eigenvectors untuk mendapatkan hasil yang optimal. Pada pengolahan karhunen loeve filter menggunakan eigenvector 15 , hal ini dikarenakan nilai yang dihasilkan memunculkan sedikit noise.

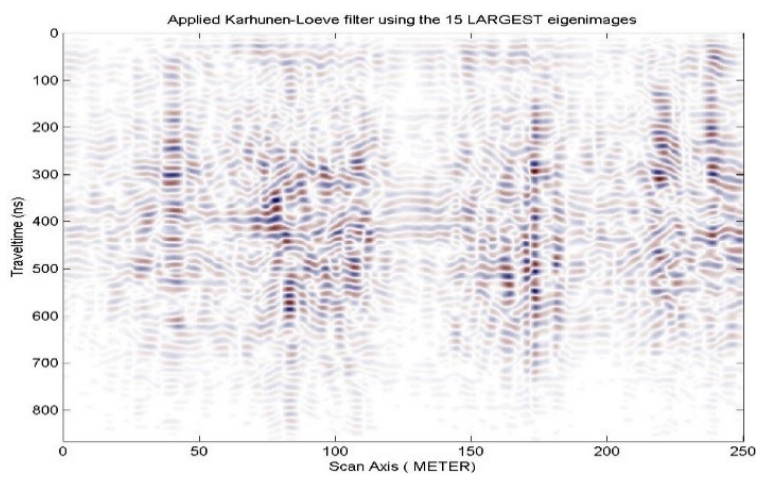

Gambar 5 Hasil setelah dilakukan proses karhunen loeve filter dengan menggunakan eigenvector 15

\section{HASIL DAN PEMBAHASAN}

Gambar 6 merupakan hasil rekaman data GPR pada lintasan 2 di bagian 1, 2 dan 3. Pada penampang radargram tersebut memperlihatkan lapisan yang cenderung turun dari arah barat menuju arah timur, penurunan lapisan dimulai dari bagian 2 yang terus merunun sampai pada bagian 3 .

Gambar 7 merupakan hasil rekaman data GPR pada lintasan 5 di bagian 1 dan 6 . Pada penampang radargram bagian 1 dapat dijumpai adanya kenaikan sinyal yang kemudian turun kembali pada trace 0-280 (0-100 meter), hal ini diduga karena struktur lapisan yang naik, sedangkan pada bagian 2 dijumpai juga kenaikan sinyal yang kemudian turun kembali pada awal bagian, hal ini dapat diduga karena struktur lapisan yang naik. Secara umum pada lintasan 5 bagian 1 dan 2 memiliki kecenderungan lapisan yang stabil. 


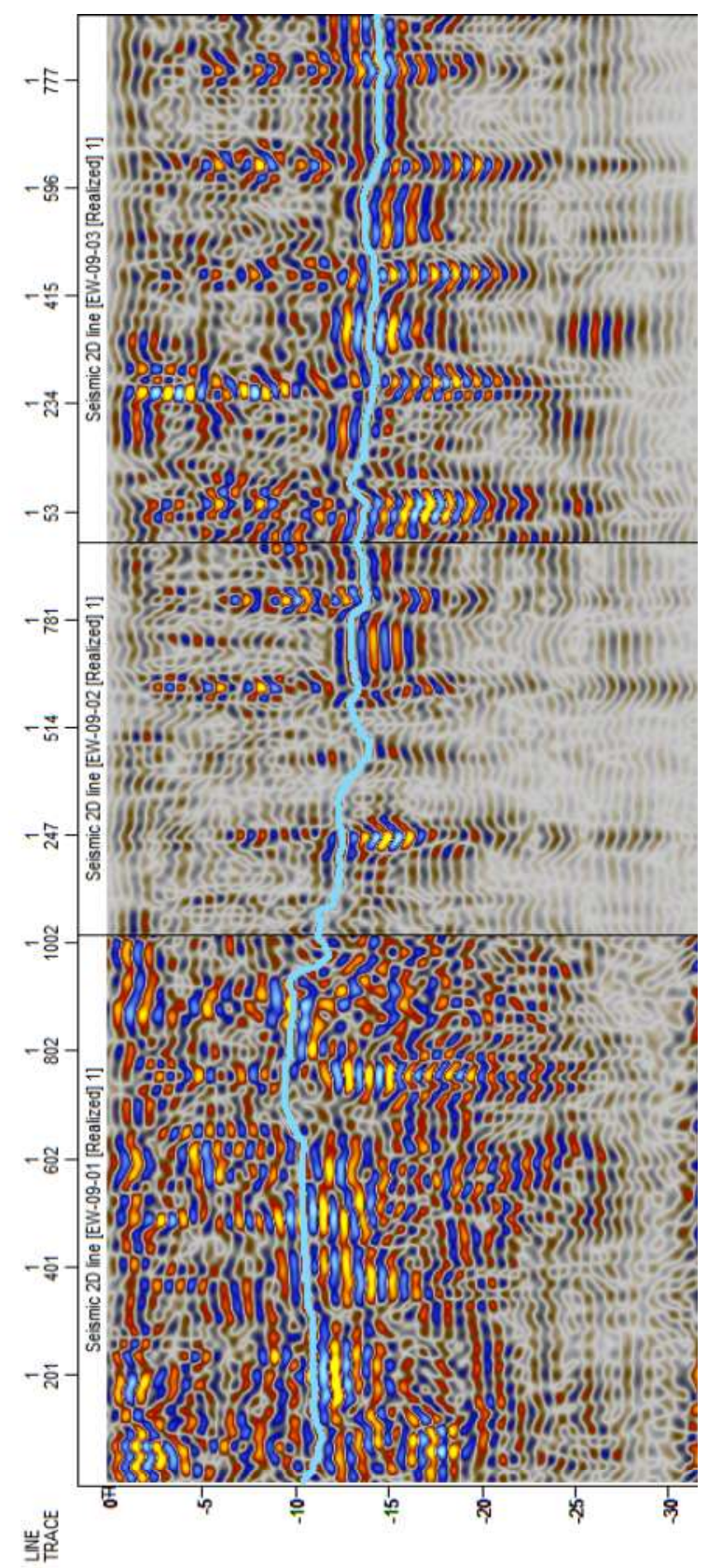

Gambar 6 Radargram hasil data lintasan 2 bagian1, 2 dan 3

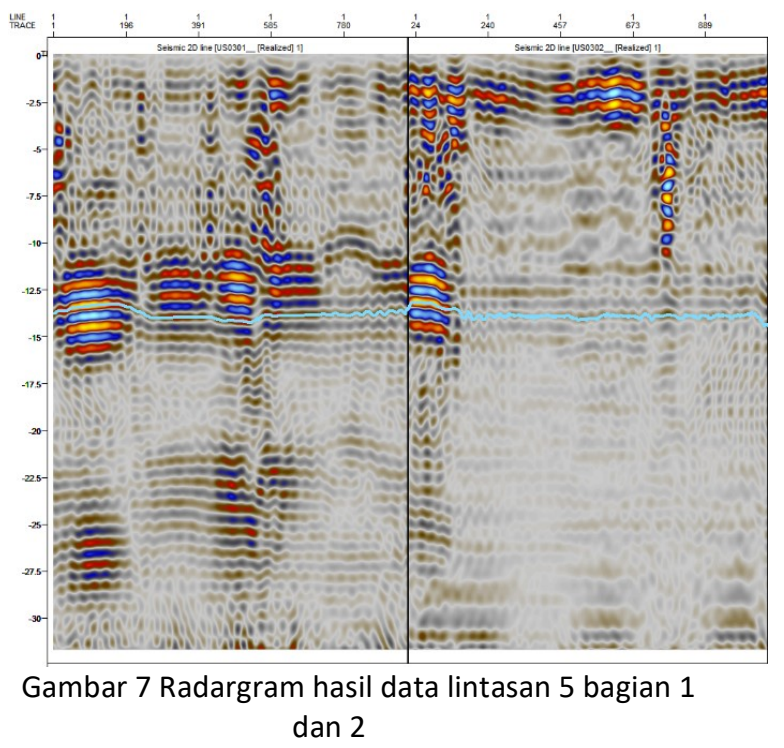

Pendugaan menggunakan metoda GPR telah dilakukan dengan mempergunakan GPR Mala dengan frekuensi antenn $25 \mathrm{Mhz}$, pembahasan dalam sub-bab ini merupakan analisis gabungan dari hasil interpretasi data GPR yang telah dilakukan. Dari analisis ini diharapkan dapat memprediksi struktur lapisan bawah permukaan.

Dari hasil interpretasi data GPR yang telah dilakukan lapisan bawah permukaan di daerah penelitian memiliki kecenderungan naik turun, walaupun naik turun lapisan tersebut hanya dalam interfal 0-4m. Pada gambar 4. 25 memperlihatkan peta hasil dari lapisan bawah permukaan dengan menggunkan GPR, dapat dilihat pada utara tanggul memiliki lapisan yang kurang rata, pendugaan karena lapisan bawah permukaan yang tidak rata dikarenakan adanya efek dari semburan lumpur sidoarjo. Dapat dilihat pada lintasan 2 yang memiliki kecenderungan lebih rendah dibanding lainnya hal ini dikarenakan lintasan ini hanya berjarak 300 meter dari sisi utara tanggul. Untuk lintasan lain didominasi oleh naik turunnya lapisan atau ketidak setabilan lapisan. 


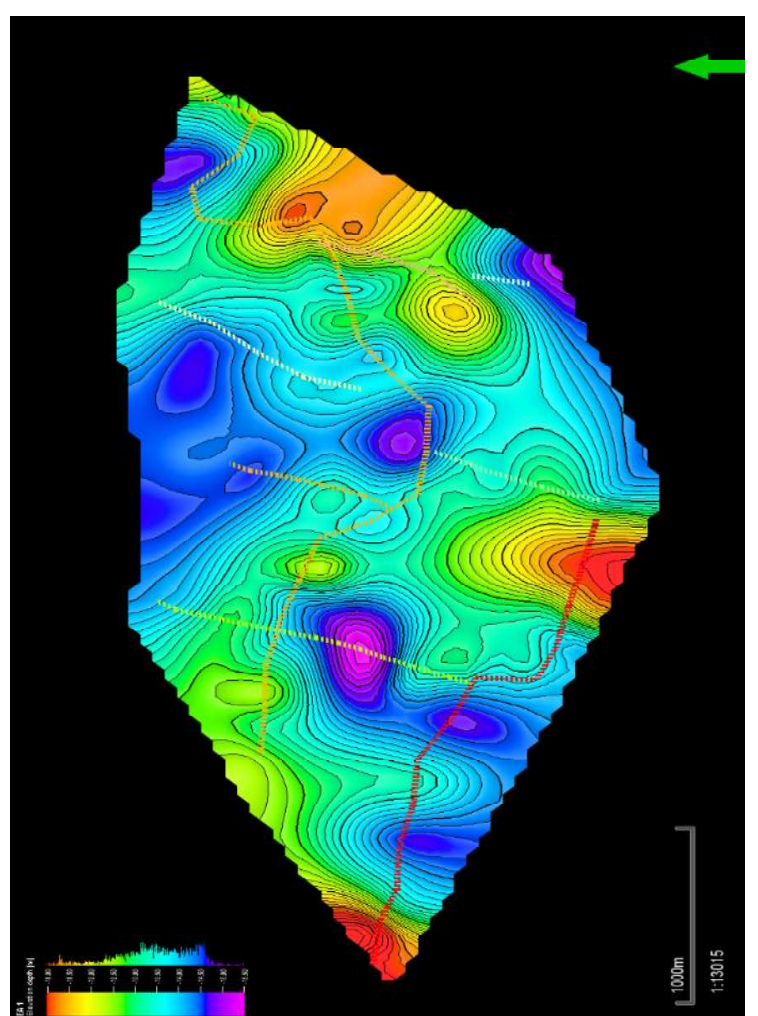

Gambar 8 Peta 2D Lapisan pada daerah pengukuran

1. Untuk mendapatkan hasil yang lebih baik dan akurat, lintasan pengukuran dapat diperbanyak dan memperluas daerah pengukurannya.

2. Perlu dilakukan penelitian dengan metode geofisika yang lainnya sebagai pembanding hasil lapisan bawah permukaan.

\section{Ucapan Terima Kasih}

Penulis mengucapkan terima kasih kepada dosen-dosen pembimbing Bapak Amien Widodo dan Bapak Firman Syaifudin atas ide penulisan dan pengarahnnya selama proses penelitian hingga selesai.

\section{DAFTAR PUSTAKA}

Allen, R.L. (1979). "Studies In Fluviatile Sedimentation: Anelementary Geometric Model For The Connectedness Of Avulsion-Related Channel Sand Bodies". Sedimentary Geology, vol.24, pp.253-267.

Badri, I., Setyanto, H., dkk. (2007). Peta Geologi Kabupaten Sidoarjo skala 1: 100.000. Badan Penaggulangan Lumpur Sidoarjo, Sidoarjo.

\section{PENUTUP}

Kesimpulan

Kesimpulan yang didapat dari penelitian ini antara lain.

1. Terdapat beberapa lokasi naik turunnya lapisan atau ketidak stabilan lapisan, yang ditunjukan dengan penampang radargram dan peta lapisan 2D yang dihasilkan oleh GPR. Pada setiap lintasan pengukuran selalu ditemukan naik turunnya lapisan walau hanya bersekitar 0-4 meter.

2. Dengan banyaknya dugaan naik turunnya lapisan yang terdapat di daerah pengukuran, memperlihatkan bahwa daerah penelitian tersebut relatif tidak stabil yang di sebabkan oleh semburan Lumpur Sidoarjo.

\section{Saran}

Saran yang dapat diberikan berdasarkan hasil dan kesimpulan untuk membangun hipotesahipotesa selanjutnya antara lain.

Budiono, Kris., Handoko, \& Hermawan, U. (2010). "Penafsiran Struktur Geologi Bawah Permukaan di Kawasan Semburan Lumpur Sidoarjo, Berdasarkan Penampang Ground Penetrating Radar (GPR)". Jurnal Geologi Indonesia, vol. 5, pp. 187-195.

Widodo, A. (2007). Memahami Bencana Gunung Lumpur: Kasus Lumpur Panas Sidoarjo. Surabaya: ITS Press. 